\title{
NONLINEAR FINITE ELEMENT ANALYSIS OF CONTINUOUS WELDED RAIL-BRIDGE INTERACTION: MONITORING-BASED CALIBRATION
}

\author{
Alfred STRAUSS ${ }^{1}$, Martina ŠOMODÍKOVÁ ${ }^{2}$, David LEHKÝ ${ }^{2}$, \\ Drahomír NOVÁK ${ }^{2}$, Konrad BERGMEISTER ${ }^{1}$ \\ ${ }^{1}$ Institute of Structural Engineering, Department of Civil Engineering and Natural Hazards, University of Natural \\ Resources and Life Sciences, Peter-Jordan-Straße 82, 1190, Vienna, Austria \\ ${ }^{2}$ Institute of Structural Engineering, Faculty of Civil Engineering, Brno University of Technology, Veveř́ 331/95, 60200, \\ Brno, Czech Republic
}

Received 15 August 2017; accepted 16 May 2018

\begin{abstract}
Continuous welded rail is of high interest to operators of railway infrastructure facilities because of the reduced maintenance work and better train driving dynamics it offers. However, the application of continuous welded rail, in particular associated with its interaction with the superstructures of e.g. bridges, requires special caution with regard to the rail stresses in the transition area between the structure and the free field. These stresses are not only influenced by thermal deformations of the bridges but also by the clamp systems between the rails and e.g. the bridge. In general, these connectors are represented by spring elements during modelling, which: (a) causes singularities in the stress distributions in the rails, and (b) cannot capture all the mechanical system changes occurring due to loading, thermal effects, etc. The target of this paper is to present an alternative way of modelling the connection between rails and bridge superstructure based on composite materials which can overcome the disadvantages of the spring model. In particular, a nonlinear model of the whole system was developed for ballasted and non-ballasted track. Special attention was paid to the calibration of railbridge interaction and boundary conditions using measured data and code specifications. The aim of this study was to use the results of in-situ measurements to analyse the admissible stress in rails due to their interaction with a bridge caused by temperature loading.
\end{abstract}

Keywords: continuous welded rail, rail-bridge interaction, connectors based on composite materials, temperature loading, admissible stress capacity, monitoring-based calibration, non-linear finite element modelling.

\section{Introduction}

Continuous welded rail (CWR) is loaded by longitudinal stress caused by seasonal temperature changes, the bending of the supporting structure as well as the braking or acceleration of traversing trains. Those types of loads are specified in the national codes as well as in Eurocode 1 (EN 1991-2:2003). The coupling stiffness in the longitudinal direction between track and bridge is an additional load case that has to be taken into account in the assessment of stress in CWR. This stress results from the nonlinear stiffness performance between the rail and the moving bridge structure beneath it, which has a different temperature to the rail. The stiffness performance increases when a train traverses the track, causing it to enter the "loaded" condition. This specific phenomenon has not been mentioned in the existing codes even though it is a common occurrence due to the specific nature of CWR. The lon- gitudinal coupling between rail and bridge is an essential aspect of CWR. In the case of a ballasted track, the ballast plays the role of this coupling interface. In the case of slab track, this role is assumed by the fastening system used. The behaviour of the system (elastic or plastic) is characterized by the deformation state of this coupling interface.

Nonlinear modelling is regarded as a suitable tool for modelling longitudinal stiffness and describing the influence of the structure on rail stress. However, a realistic load can only affect the entire bridge over a period of time. Currently, there is not enough information on ways of determining a value for the coupling stiffness in the longitudinal direction that is caused by traversing trains. It is therefore essential to conduct an evaluation of coupling stiffness based on in-situ monitoring in order to identify reliable values against which nonlinear models can be calibrated.

\footnotetext{
${ }^{\star}$ Corresponding author. E-mail: lehky.d@fce.vutbr.cz
} 
Only CWR offers suitable serviceability with respect to today's increasing train speeds, as the deformation of joints often affects the geometry of non-CWR track, which results in considerable joint maintenance requirements. On the other hand, it is necessary, in order to guarantee safety and stability, to restrict the longitudinal stress occurring in CWR. Several research works which specifically investigate stability issues are presented in Kerr (1978, 1980) and Lim et al. (2003). When various bridge types are loaded, changes in the coupling stiffness increase the stress within the rail-bridge interface. This increase clearly needs to be considered. A significant increase in the stress affecting the elastic components along the track-bridge coupling interface, accompanied by a decrease in stress in the rails, is caused by multiple cycles of traversing trains that occur after a seasonal decrease in temperature.

The investigation of longitudinal loads and their influence on the forces in CWR on bridge decks has been discussed intensively in the last 20 years. This was triggered by recommendation 774-3R of Union Internationale des Chemins de fer (UIC 2001), as well as by the Eurocode 1 (EN 1991-2:2003) standard published by the European Committee for Standardization, which provides information on loads on bridges, design methods and approaches. In order to keep the computational effort at a reasonable level, EC-1 (2003), DIN-Fb 101 (2003) and UIC Code 774$3 \mathrm{R}$ (2001) provide the nonlinear stiffness law as a relationship between resistance and displacement for ballasted as well as non-ballasted track. It is described by bilinear functions. These functions may vary depending on the track type and the loading situation (see Figure 1).

DIN-Fb 101 (2003) recommends a track resistance value of $k_{3}=20 \mathrm{kN} / \mathrm{m}$ for ballasted track and a value of $k_{2}=30 \mathrm{kN} / \mathrm{m}$ for a non-ballasted track, in both cases for the unloaded condition. As a result, a value of $k_{1}=60 \mathrm{kN} / \mathrm{m}$ emerges for the loaded condition caused by moving trains, both for a ballasted track as well as for a non-ballasted track. Therefore, the equilibrium of forces changes from the unloaded to the loaded situation as the train traverses the track, i.e. from $30 \mathrm{kN} / \mathrm{m}$ to $60 \mathrm{kN} / \mathrm{m}$. In other words, it increases by a factor of two for a non-ballasted track. The ballasted track amplifies the restoring force from $20 \mathrm{kN} / \mathrm{m}$ to $60 \mathrm{kN} / \mathrm{m}$, i.e. by a factor of three. Additional forces will arise, as this transition occurs over a short time period. Only a few authors have addressed this subject, e.g. Kupfer (2002) and Ruge et al. (2004).

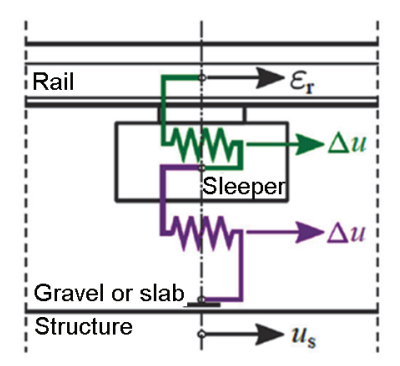

a)
Frýba (1996) and Esveld (2001) present detailed treatments of longitudinal stress in their books. In addition, the subject is addressed in several journal papers (Ruge et al. 2004, 2005a, 2005b) and papers published in conference proceedings (Ruge et al. 2007; Simões et al. 2007). These papers show that load cases involving temperature changes and bending phenomena as well as braking and acceleration manoeuvres can lead to considerable longitudinal stress. However, the often-used superposition approach for different load cases works against the nonlinear properties of the system. A nonlinear treatment of several load cases is introduced in Ruge et al. (2005b). Here, each loading episode is treated one after the other, forming a sequence. A memory system is established which utilises the history of deformations caused by previous loads as an input for the assessment of the current state of the loading system. Nevertheless, a nonlinear combination of the resulting stress can be used to bring the system's nature closer to that of a realistic situation.

The lateral buckling behaviour of CWR due to compression forces caused by temperature changes was already being discussed in the early 80's by Klaaßen and Schmälzlin (1980), Gerlich and Pahnke (1981, 1982) and Prommersberger and Rojek (1981, 1985). In 1983, the Office for Research and Experiments (ORE, now the European Rail Research Institute, ERRI) of the International Union of Railways (UIC) published a work on the theoretical and practical issues concerned with the behaviour of CWR laid over bridge structures subjected to temperature changes in rail and bridge (Colnat, Brems 1983). In addition, more detailed examinations exist with respect to the influence of the bending of supporting structures on the longitudinal stress in rails reported by Pahnke (1998) and regarding track-bridge interaction in UIC 774-3R (2001). In Ruge et al. (2009a, 2009b), the focus is placed on stresses additional to those arising from seasonal temperature changes due to the sudden change in the coupling stiffness between track and bridge during the traversing of trains. The history of CWR and the development of the investigation of track-bridge interaction effects as well as the background to the procedure for evaluating additional rail stresses are also presented in Wenner et al. (2016a, 2016b). A detailed study of wheel-rail interaction was performed by Cazzani et al. (2016). Longitudinal deformation, which is often neglected by other authors, lies at the centre of their

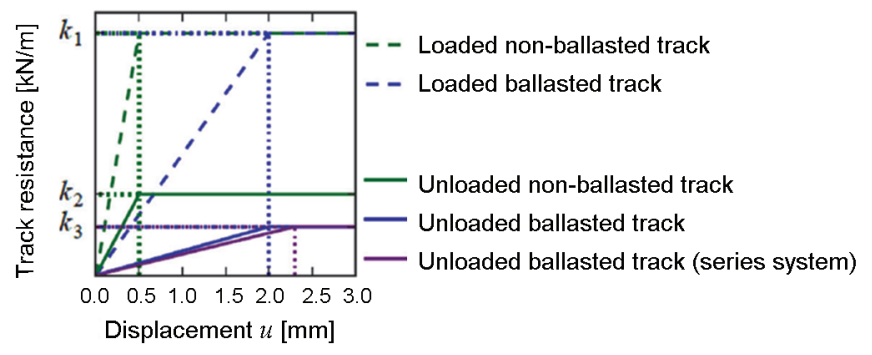

b)

Figure 1. a) Spring models of non-ballasted and ballasted track; b) track-bridge interaction model 
research. Practical design aspects concerning track-bridge interaction can be found in Chaudhary and Sinha (n.d.) and Monnickendam (2006). Some of these aspects are implemented in Eurocode 1 (EN 1991-2:2003). One example is the fact that movements within the bridge cause track displacements which will result in rail stress.

As was mentioned previously, the interaction between bridge and rail is an important parameter in railway bridge design. Therefore, a measurement campaign was performed together with nonlinear model calibration to investigate the interaction process and predict the longitudinal stress in rails and in concrete slab track. The intention was to develop a model with the ability to reflect the results gained by monitoring systems installed on realworld bridges. This will subsequently enable the use of the verified model with bridge systems in general.

Stress in rails is caused by temperature changes within them, the bending of the bridge deck, the braking and acceleration of trains, and also by temperature changes in the bridge transferred via rail-bridge interaction. This stress particularly needs to be limited in CWR. An essential parameter for quantifying the effects of the interaction between rail and substructure is the free expansion length of the bridge, defined as the distance between the thermal reference point and the flexible end point of the supporting structure.

In general, additional stress in CWR on a bridge should not exceed the admissible stress capacity defined in DIN$\mathrm{Fb} 101$ (2003) as follows:

- Tension stress threshold $\sigma_{\text {tension }}=112 \mathrm{MPa}$ if bending is considered as a load case;

- Tension stress threshold $\sigma_{\text {tension }}=92 \mathrm{MPa}$ if bending is neglected;

- Compression threshold for a buckling ballasted track $\sigma_{\text {compression }}=72 \mathrm{MPa}$;

- Compression threshold for a slab (non-ballasted) track $\sigma_{\text {compression }}=92 \mathrm{MPa}$.
The admissible stresses above are based on the total available rail stress $\sigma_{\text {safe }}=470 \mathrm{MPa}$, which has to be reduced by:

- Residual stress from rail production $\sigma_{\mathrm{E}}=80 \mathrm{MPa}$;

- Bending tensile stress due to wheel load $\sigma_{\mathrm{Q}}=158 \mathrm{MPa}$;

- Stress resulting from temperature change within the rail $\sigma_{\mathrm{T}}=E \alpha \Delta T=120 \mathrm{MPa}$ considering the modulus of elasticity $E=2.1 \times 10^{5} \mathrm{MPa}$, the temperature difference $\Delta T=50^{\circ} \mathrm{C}$, and the thermal coefficient $\alpha=1.15 \times 10^{-5}$.

Reducing the safe rail stress $\sigma_{\text {safe }}$ yields an admissible margin for an increase in rail stress due to track-bridge interaction $\sigma_{\text {tension }}=470-80-158-120=112 \mathrm{MPa}$.

Note that the aim of the paper was to study rail-structure interaction and transfer of temperature effects from the bridge to the rail, not the complex modelling of passing train. Therefore, instead of analysing the stresses caused by traversing train, the code-defined maximum stress $158 \mathrm{MPa}$ has been used.

In accordance with Eurocode 1 (EN 1991-2:2003) as well as DIN-Fb 101 (2003) and UIC 774-3R (2001), additional stress resulting from track-bridge interaction which is larger than the permissible values should lead to the use of expansion devices being considered. DIN-Fb 101 (2003) uses the classical safety concept where the safety $S_{\text {safe }}$ is determined by a global safety factor $v$ as:

$$
S_{\text {safe }}=\frac{R}{v},
$$

where: $R$ - resistance; $v$ - safety factor.

The main target of this paper is to present an alternative way of modelling the connection between rails and bridge superstructure based on composite materials which can overcome the disadvantages of the spring model. In particular, a nonlinear model of the whole system was developed for ballasted and non-ballasted track. Special

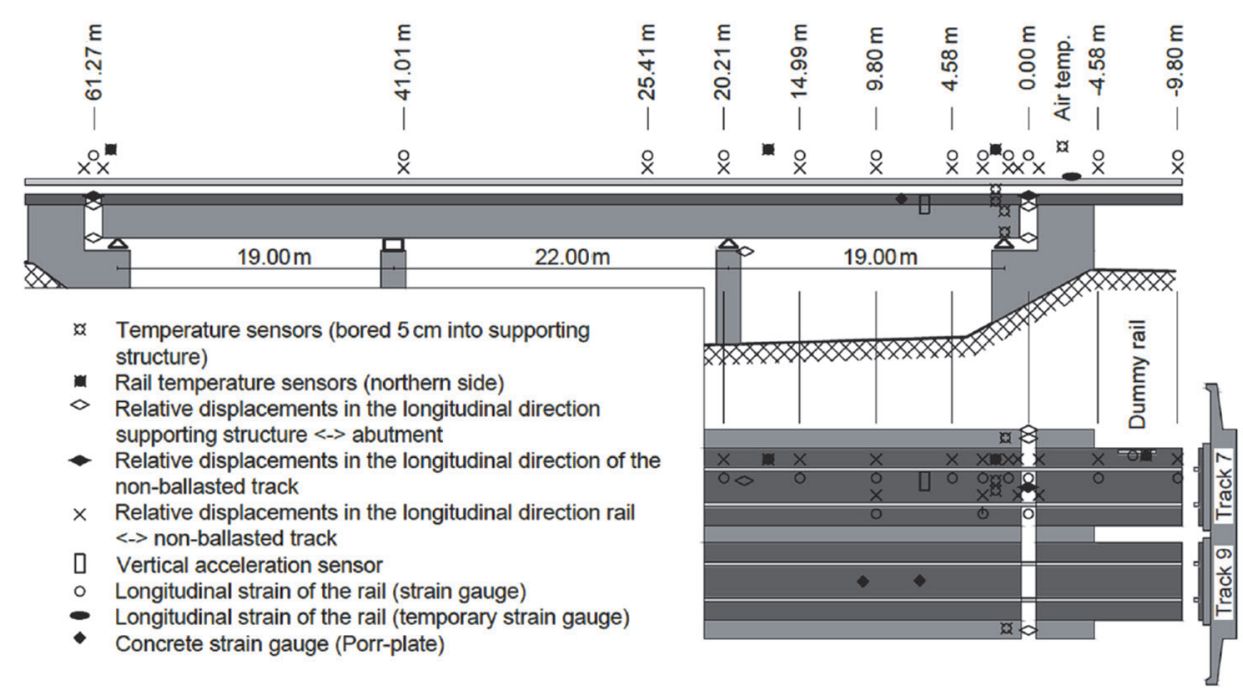

Figure 2. Static scheme of the L110 Bridge and a depiction of the monitoring system (north view) 


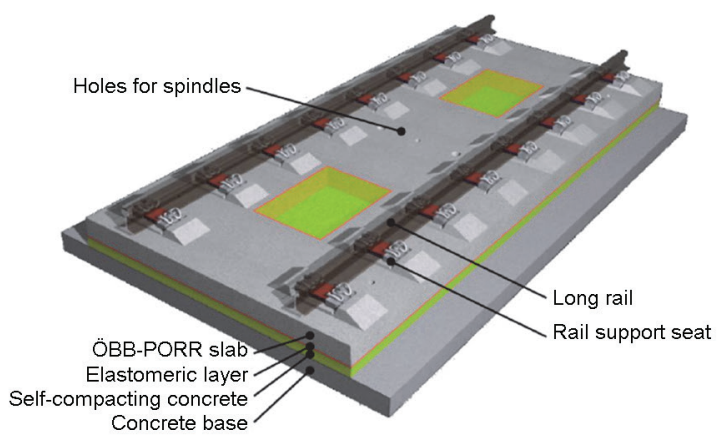

a)

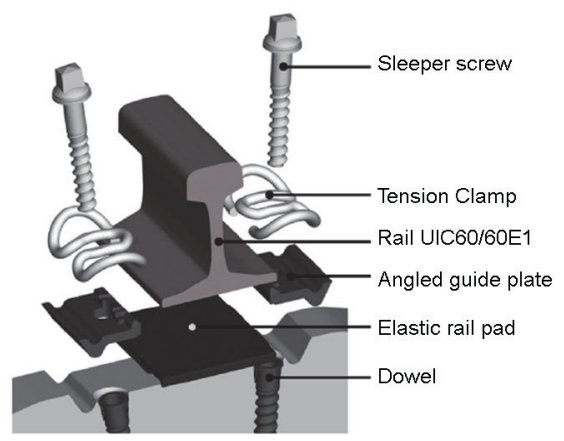

b)

Figure 3. a) Elastically supported slab - System ÖBB-PORR; b) Vossloh rail fastening system with rail UIC60/ 60E1

attention was paid to the calibration of rail-bridge interaction and boundary conditions using measured data and code specifications. The aim of this study was to use the results of in-situ measurements to analyse the admissible stress in rails due to their interaction with a bridge caused by temperature loading.

\section{Case study: the L110 Bridge}

\subsection{Description of the bridge and monitoring system}

The L110 Bridge is a part of a new Austrian railway line connecting St. Pölten to Vienna. The bridge has a reinforced concrete structure with three spans; two of them with a span length of $19 \mathrm{~m}$ extending from the piers to the abutments and one central span with a length of $22 \mathrm{~m}$ (see Figure 2). The eastern pier of the bridge serves as a longitudinally fixed bearing. Both the piers and the abutments are founded on bored piles with diameter $d=120 \mathrm{~cm}$.

The bridge is constructed from prestressed reinforced concrete and has a rectangular shape. Pluvial water drainage is provided by the cambered bridge deck cross-section (with 2.5\% slopes running from the centre of the bridge to its extremities). The track rests on System ÖBB-PORR elastically supported slabs (PORR AG 2016), see Figure 3a. Each rail is supported by 8 rail seats on each slab plate. The rails are fastened by Vossloh clamps across the entire bridge (see Figure 3b).
Extensive monitoring systems were designed for the bridge structure. In addition to monitoring the rail stresses, they were programmed to record: (a) the shear pressure resistance, (b) the lateral displacement resistance, (c) the rail temperature, (d) the temperature of the supporting structure and (e) the relative movements of the track and bridge. This information was used as input data and to support the verification of the developed nonlinear model of track-structure interaction. Selected sensors and its placement on the bridge are depicted in Figure 4.

At the transitions between the bridge and the abutments attention has been paid to the longitudinal displacements of the bridge. As the eastern pier fixedly supports the bridge in the longitudinal direction, the effect of a $19 \mathrm{~m}$ span could be observed on the eastern abutment, while on the western abutment one could observe the effect of $41 \mathrm{~m}$ of combined longitudinal spans (see Figure 2). The metrological instrumentation is focused on Track 7 as obvious from Figure 2 (since Track 9 was built at a later time) at the joint between the bridge and the western abutment. The CWR profiles span this transition region; the rail fastenings have a defined reduced yielding resistance and the rails are free to slide along them when the relative movement of the bridge requires it. The rail profiles are welded in sections positioned on the abutments and are elastically supported through the track supporting layer by the non-ballasted track. Thus, the rails, through their fastening system, connect the bridge to the abutment
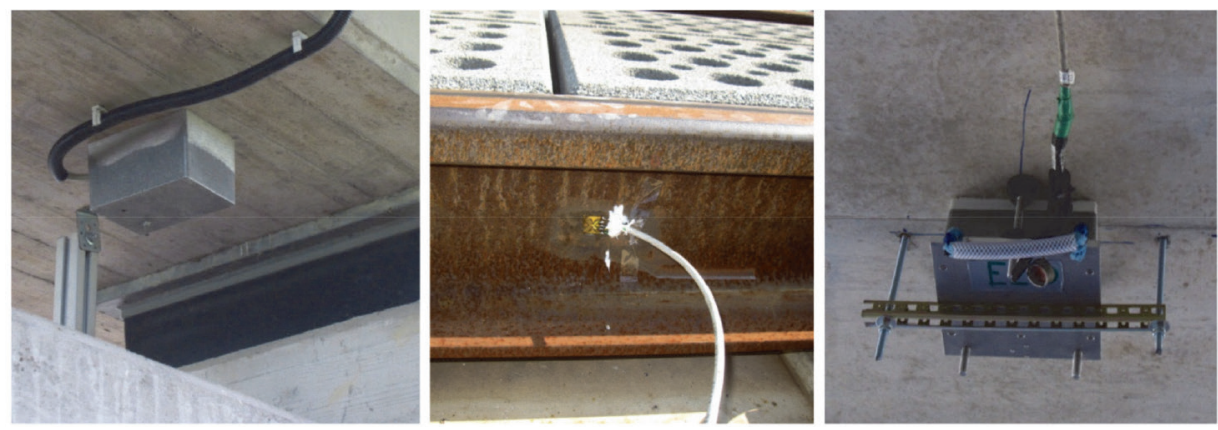

Figure 4. Examples of selected sensors: a longitudinal displacement sensor placed next to the bearing (left), electrical strain gage placed on the rail (middle), and an accelerometer placed on the bottom surface of the bridge slab (right) 


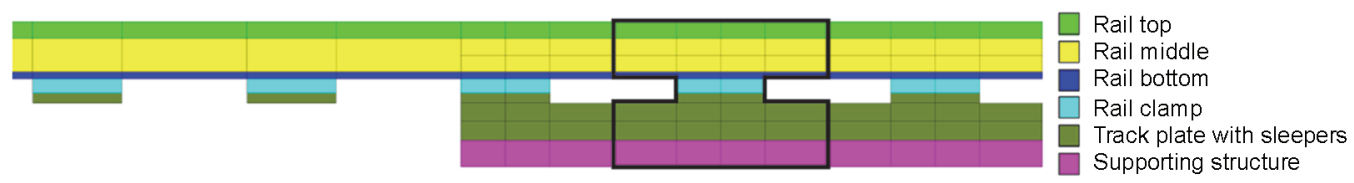

Figure 5. Part of the model of the structure showing individual components of the bridge and rail system

in the longitudinal direction. The force-displacement behaviour of this interaction was the main subject of monitoring. The monitoring results served as the first step for calibrating thenumericalmodel. Themodelwassubsequently used to expand the research to bridges with different spans, temperature loads, and track types (ballasted and nonballasted track).

\subsection{Numerical model, rail clamp calibration}

A nonlinear finite element method (FEM) model of the L110 Bridge in Austria has been developed in order to investigate rail-bridge interaction and predict longitudinal stresses occurring in rails due to temperature loading. The whole system of the bridge supporting structure-rail supports-rail fastenings-rails has been modelled in ATENA software (Červenka et al. 2012) with consideration given to material nonlinearity. In general, the analysed bridge is a three-dimensional structure. But with respect to its dimensions, boundary conditions, and loading, the twodimensional model provides sufficiently accurate results while maintaining reasonable time-consuming performance. Due to such simplification, we were able to perform an extensive study using the nonlinear FEM model of the bridge. With respect to the great computational effort required for nonlinear modelling, only the rails and parts of the track under the rails were modelled using 2D plane stress simplification, see Figure 5. Each component of the system (i.e. supporting structure, track plate with sleepers and rails) was modelled according to their real geometry using individual element thicknesses. Solid elastic material model with linear stress-strain law defined by the modulus of elasticity was used. The rail fastening system (referred to as a "clamp" in the following text) was modelled using simplified geometry without reproducing the physical dimensions of its individual parts. Here, SBETA material model which includes the effects such as nonlinear behaviour in compression including hardening and softening, fracture of concrete in tension based on the nonlinear fracture mechanics, biaxial strength failure criterion, reduction of compressive strength after cracking, etc. (for details see Červenka et al. 2012) was finally used as described below. A mesh was created for the FEM static analysis using quadrilateral element type.

In traditional models, spring systems are used for simulating the complex rail-structure interaction. In general, these linear spring systems defined in a closed form do not take into account the load dependence of the interaction properties and the fact that the contact zones are surfaces with changing load-dependent area sizes. The proposed contact zone nonlinear model considers these effects.

The aim of a rail clamp is to transfer horizontal and vertical forces from the rail to the supporting structure. In order to achieve the realistic representation of these phenomena the nonlinear FEM model needs to be calibrated with respect to experimental measurements and code specifications. At first, several models with different clamp geometries (a trapezoid shape, a double-rectangular shape and a simple rectangular shape, see Figure 6) and different material models (bi-linear steel, SBETA material, the Drucker-Prager model, and a material model with smeared reinforcement in various orientations or combinations of materials for different clamp parts) were tested to capture the horizontal (shear) and vertical (compressive) stiffness of the track-rail system. The concept of incremental step by step analysis with force increments was used in order to achieve the target values of horizontal and vertical loading according to code specifications and experimental results. Iterative solution using standard Newton-Raphson method was used to solve the set of non-linear equations which represents the out-of-balance forces during a load increment (for details see Červenka et al. 2012).

Since the models with trapezoid or double-rectangular shapes did not ensure the correct behaviour occurred in either shear (horizontal loading, see Figure 7a) or compression (vertical loading, see Figure $7 \mathrm{~b}$ ), the clamp was finally modelled simply as a single block with a thickness of $0.2 \mathrm{~m}$ made of SBETA material (Chen, Saleeb 1982) with smeared reinforcement by means of a linear stress-strain diagram defined by modulus of elasticity.
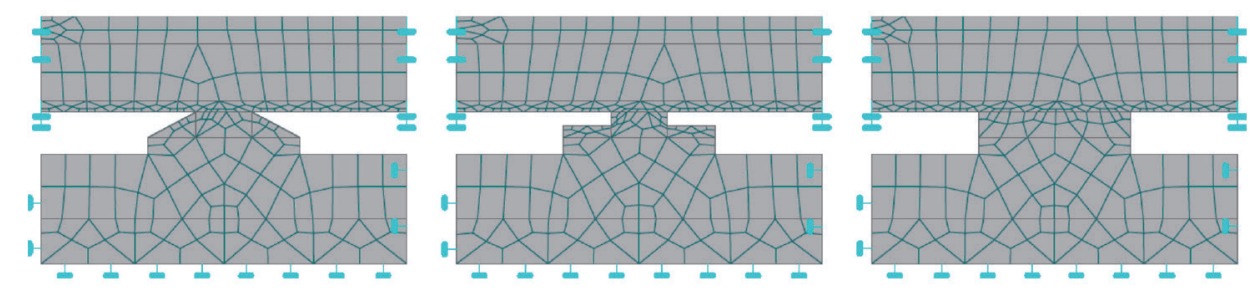

Figure 6. FEM models with different clamp geometries: a) trapezoidal shape; b) double-rectangular shape; c) simple rectangular shape 


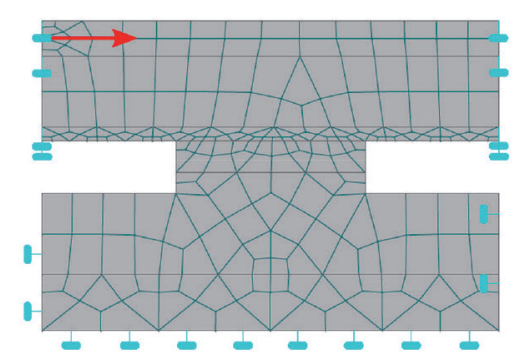

a)

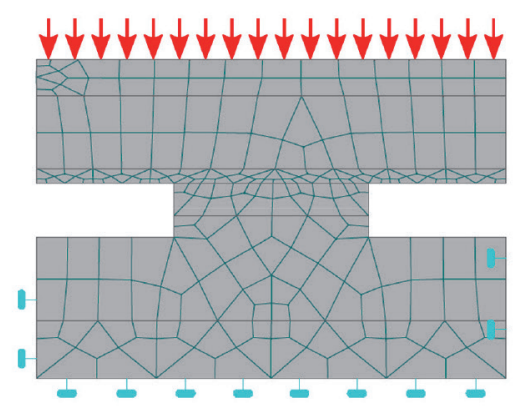

b)

Figure 7. a) Horizontal and b) vertical loading of the clamp for calibration of the system

The smeared reinforcement was used to capture the different stiffness and bearing capacity of the system in the horizontal and vertical direction. Parametric analyses of the orientation and ratio of the reinforcement were performed so as to determine the proper response of the clamp model to horizontal as well as vertical loading. According to the relevant code specification (Figure 1), the unloaded track resistance limit for horizontal loading and a track supported by concrete slabs (non-ballasted track) is $20 \mathrm{kN} / \mathrm{m}\left(k_{2}\right.$ in Figure $\left.1 \mathrm{~b}\right)$. The L110 Bridge with a distance between clamps of $60 \mathrm{~cm}$ had an unloaded track resistance of $12 \mathrm{kN} / \mathrm{m}$. This is also in good agreement with the results of laboratory measurements, see Figure 8a. In the case of vertical loading, laboratory tests obtained a $1 \mathrm{~mm}$ vertical displacement for a $50 \mathrm{kN}$ load (Figure $8 \mathrm{~b}$ ). The gained data were utilized for the calibration of clamp material models. A rail clamp for track supported on pre-stressed concrete sleepers laid on gravel ballast (ballasted track) was calibrated at the same time as the calibration of rail clamps for non-ballasted (slab) track was taking place. More details about the experimental results are documented in Karimi (2017).

The clamp for ballasted track is less stiff compared to that used with non-ballasted track due to the employed system of two springs connected in series (Figure 1a). As a result, the calibrated parameters of the model (especially modulus of elasticity $E$ ) had to be modified. Since the stiffness of the track-rail system is defined using the clamp parameters, no additional extension of the model was used. The unloaded track resistance limit for horizontal load- ing for the L110 Bridge is $12 \mathrm{kN} / \mathrm{m}\left(k_{3}\right.$ and the purple line in Figure $1 \mathrm{~b}$ ), which is $7.2 \mathrm{kN} / \mathrm{m}$ for a distance between clamps of $60 \mathrm{~cm}$. In both cases the models were tested for a loaded situation, i.e. when subjected to the simultaneous action of horizontal and vertical loading. Here, in order for the system to have sufficient stiffness $\left(k_{1}\right.$ in Figure $\left.1 \mathrm{~b}\right)$ it was necessary to increase the modulus of elasticity of the SBETA material. The resulting parameters for non-ballasted track are as follows:

- SBETA material: modulus of elasticity $E=36.5 \mathrm{MPa}$ ( $E=240 \mathrm{MPa}$ for a loaded situation), tensile strength $f_{\mathrm{t}}=0.65 \mathrm{MPa}$, compressive strength $f_{\mathrm{c}}=3.5 \mathrm{MPa}$, and fracture energy $G_{\mathrm{f}}=6 \mathrm{~N} / \mathrm{m}$;

- Smeared reinforcement: bi-linear stress strain law without hardening, 2 layers with direction $\pm 15^{\circ}$, reinforcement ratio 0.5 , modulus of elasticity $E=342 \mathrm{MPa}$, yield stress $f_{\mathrm{y}}=0.65 \mathrm{MPa}$.

The parameters of the clamp material models for ballasted track are as follows:

- SBETA material: modulus of elasticity $E=11.5 \mathrm{MPa}$ ( $E=57.5 \mathrm{MPa}$ for a loaded situation), tensile strength $f_{\mathrm{t}}=0.15 \mathrm{MPa}$, compressive strength $f_{\mathrm{c}}=3.5 \mathrm{MPa}$, and fracture energy $G_{\mathrm{f}}=6 \mathrm{~N} / \mathrm{m}$;

- Smeared reinforcement: bi-linear stress strain law without hardening, 2 layers with direction $\pm 90^{\circ}$, reinforcement ratio 1.0, modulus of elasticity $E=14.5 \mathrm{MPa}$, yield stress $f_{\mathrm{y}}=1.3 \mathrm{MPa}$.

The calibration results for both systems subjected to horizontal as well as vertical loading and also to the simultaneous action of both are depicted in Figures 8 and 9.

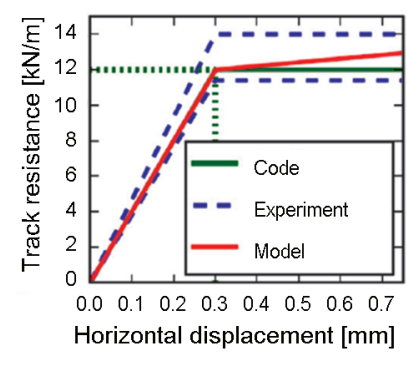

a)

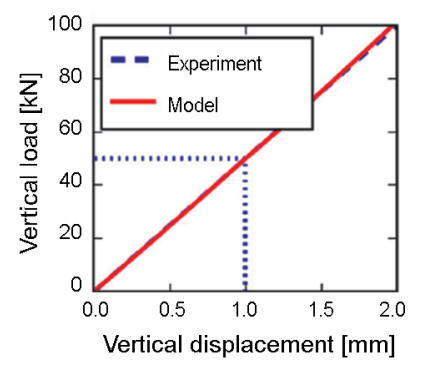

b)

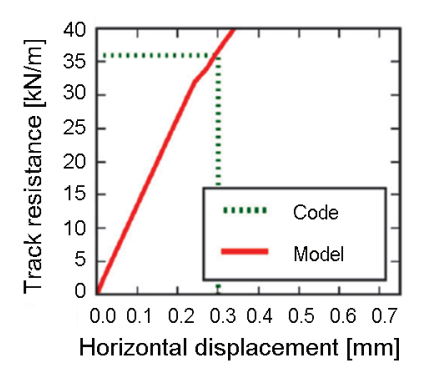

c)

Figure 8. Calibration of the rail clamp for non-ballasted track: a) horizontal loading;

b) vertical loading; c) simultaneous action of horizontal and vertical loading 


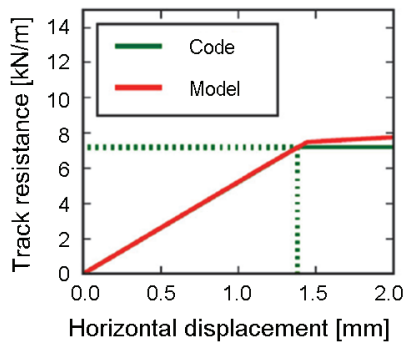

a)

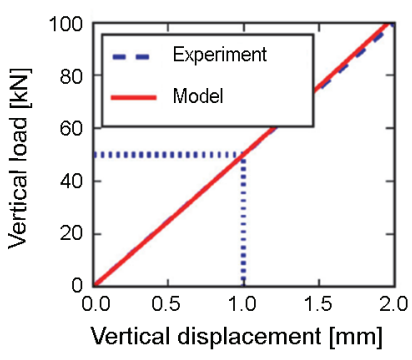

b)

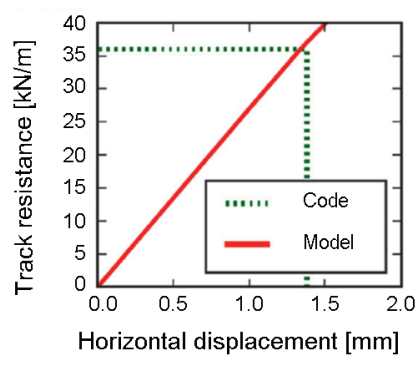

c)

Figure 9. Calibration of the rail clamp for ballasted track: a) horizontal loading; b) vertical loading;

c) simultaneous action of horizontal and vertical loading

\subsection{Calibration of rail boundary conditions}

The next step in modelling was the calibration of rail boundary conditions. First, different boundary conditions (free rail, fixed rail or springs at the ends of the rail, see Figure 10) were tested. The rail and the supporting structure in the FEM model were loaded by temperatures $\Delta T_{\mathrm{r}}$ and $\Delta T_{\mathrm{s}}$ (Figure 11), which represent the difference between the maximum and minimum temperature value obtained over the course of 1 day/24 hours in the appropriate season via measurements taken from the rail and structure respectively, see Table 1 . The loading was applied using temperature increments up to reaching the total temperature values. The same temperature values $\left(\Delta T_{\mathrm{r}}\right.$ and $\Delta T_{\mathrm{s}}$ ) were applied throughout the rail and structure, respectively; i.e. no change of temperature with distance was considered. At the western abutment, the rail strain $\varepsilon_{\mathrm{r}}$ and bridge horizontal displacement $u_{\mathrm{s}}$ caused by the temperature loading were analysed and compared with measurements taken from the real structure (Figure 2).

The results of in-situ measurements taken during one particular day in spring were used for the calibration while measurements gained during the other three seasons (summer, autumn and winter) were used for validation of the calibrated model. Detailed spring stiffness calibration was carried out based on those results. In order to find the best value, a parametric study of the values obtained for horizontal spring stiffness $K$ from 1 to $1000 \mathrm{MPa}$ was executed. The results in Table 1 show that relatively good agreement between the measurements and numerical simulations was achieved for $K=500 \mathrm{MPa}$. Furthermore, it was discovered that a spring rail boundary condition with $K>30 \mathrm{MPa}$ leads to almost identical values of rail strain $\varepsilon_{\mathrm{r}}$ and horizontal displacement of the structure $u_{\mathrm{s}}$, respectively, as in the case of a fixed rail boundary condition, and that there is no merit in using a spring instead of a fixed rail. The fixed support also exhibits realistic behaviour: the rail strain as well as the horizontal displacement of the bridge increase with increasing temperature $\Delta T_{\mathrm{s}}$ and constant $\Delta T_{\mathrm{r}}$; see the parametric study in Figure 12. On the other hand, the free rail boundary or lower values of $K$ lead to very unstable and unrealistic values being obtained for rail strain or the horizontal displacement of the structure, respectively, for cases of loading with higher $\Delta T_{\mathrm{r}}$ (see the spring and summer rows in Table 1).

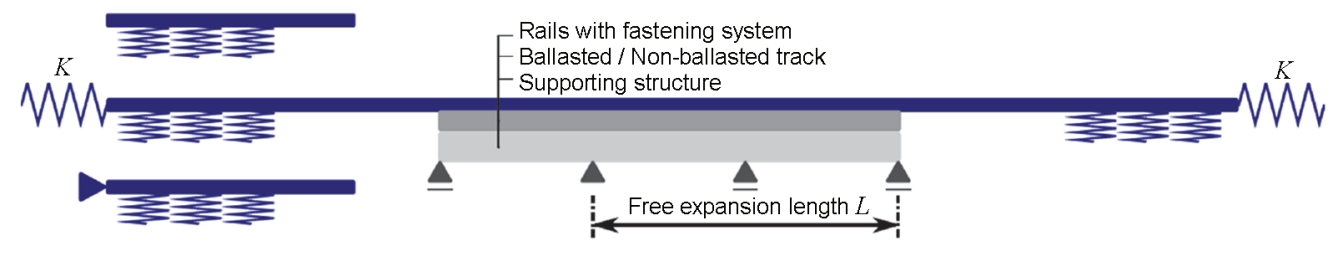

Figure 10. Boundary conditions of the rail: free rail, springs at the ends of the rail and the fixed rail

Table 1. Comparison of horizontal displacements of the structure $u_{\mathrm{s}}$ and rail strains $\varepsilon_{\mathrm{r}}$ obtained from seasonal in-situ measurements and nonlinear modelling

\begin{tabular}{|l|c|c|c|c|c|c|c|c|c|c|c|c|c|}
\hline \multirow{2}{*}{ Season } & \multicolumn{3}{|c|}{ Seasonal measurements } & \multicolumn{2}{c|}{$\begin{array}{c}\text { Modelling } \\
\text { Free rail }\end{array}$} & \multicolumn{2}{c|}{$\begin{array}{c}\text { Modelling } \\
K=14 \mathrm{MPa}\end{array}$} & \multicolumn{3}{c|}{$\begin{array}{c}\text { Modelling } \\
K=500 \mathrm{MPa}\end{array}$} & \multicolumn{3}{c|}{$\begin{array}{c}\text { Modelling } \\
\text { Fixed rail }\end{array}$} \\
\hline & $\Delta T_{\mathrm{r}}\left[{ }^{\circ} \mathrm{C}\right]$ & $u_{\mathrm{s}}[\mathrm{mm}]$ & $u_{\mathrm{s}}[\mathrm{mm}]$ & $\varepsilon_{\mathrm{r}}[\mu \mathrm{m} / \mathrm{m}]$ & $u_{\mathrm{s}}[\mathrm{mm}]$ & $\varepsilon_{\mathrm{r}}[\mu \mathrm{m} / \mathrm{m}]$ & $u_{\mathrm{s}}[\mathrm{mm}]$ & $\varepsilon_{\mathrm{r}}[\mu \mathrm{m} / \mathrm{m}]$ & $u_{\mathrm{s}}[\mathrm{mm}]$ & $\varepsilon_{\mathrm{r}}[\mu \mathrm{m} / \mathrm{m}]$ & $u_{\mathrm{s}}[\mathrm{mm}]$ & $\varepsilon_{\mathrm{r}}[\mu \mathrm{m} / \mathrm{m}]$ \\
\hline Spring & 28.03 & 1.43 & 0.41 & 320.46 & 1.43 & 15.14 & 0.94 & 322.45 & 0.49 & 360.15 & 0.49 & 360.18 \\
\hline Summer & 31.57 & 1.64 & 0.46 & 366.51 & 1.64 & 13.09 & 1.64 & 325.29 & 0.60 & 406.65 & 0.60 & 407.06 \\
\hline Autumn & 10.71 & 0.41 & 0.20 & 133.42 & 0.41 & 147.90 & 0.41 & 148.01 & 0.40 & 148.14 & 0.40 & 148.15 \\
\hline Winter & 10.80 & 0.36 & 0.31 & 142.11 & 0.36 & 146.71 & 0.36 & 146.84 & 0.36 & 146.97 & 0.36 & 146.98 \\
\hline
\end{tabular}




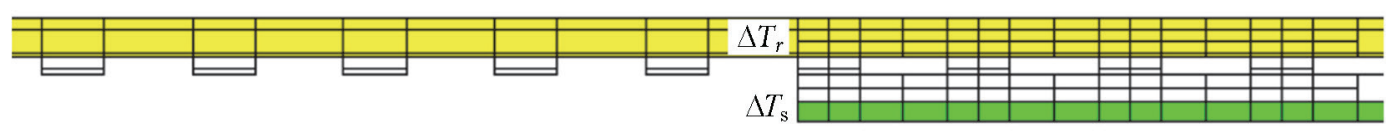

Figure 11. Part of the model of the structure loaded by temperature

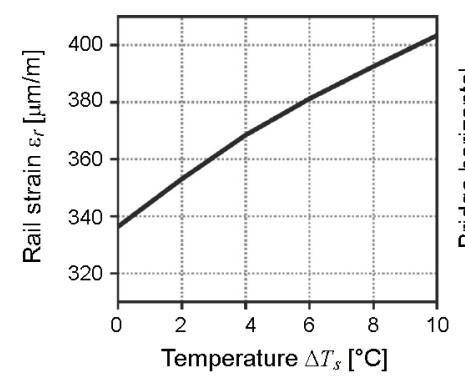

a)

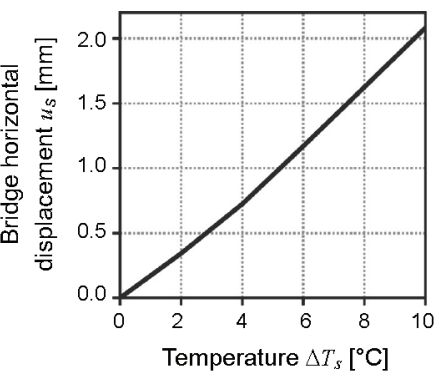

b)

Figure 12. Relationship between the increasing temperature of the structure $\Delta T_{\mathrm{s}}$ and: a) rail strain $\varepsilon_{\mathrm{r}}$ and b) bridge horizontal displacement $u_{\mathrm{S}}$ for a constant $\Delta T_{\mathrm{r}}=28.03{ }^{\circ} \mathrm{C}$ and a fixed rail boundary condition

\subsection{Temperature effects studies}

A numerical study was carried out using the now-calibrated nonlinear FEM model of the track-bridge system in order to determine the effect of bridge temperature loading on stress induced in a rail due to track-bridge interaction. This stress should not exceed the previously described admissible stress capacity. The effect of various bridge free expansion lengths (free expansion length is the length from the fixed support to the bridge abutment, see Figure 10) for both non-ballasted as well as ballasted track was also studied.

The temperature of the structure $\Delta T_{\mathrm{s}}$ was between 0 and $30^{\circ} \mathrm{C}$, and the temperature of the rail $\Delta T_{\mathrm{r}}=0$, 28 and $50^{\circ} \mathrm{C}$ (Table 2). The bridge free expansion lengths were $L=40,60,90,120$, and $150 \mathrm{~m}$. An example of the normal stress distribution in the rail caused by the imposition of various temperature loads on a bridge with a free expansion length of $40 \mathrm{~m}$ is depicted in Figure 13. From these curves the maximum stress in tension and compression was extracted (see the bullets in Figure 13 - for tension in the field and for compression above the abutment) for dif-
Table 2. Studies performed for different combinations of rail-structure temperature loading

\begin{tabular}{|c|c|c|c|c|c|c|c|c|c|c|c|c|}
\hline \multirow{2}{*}{$\Delta T_{\mathrm{r}}\left[{ }^{\circ} \mathrm{C}\right]$} & \multicolumn{10}{|c|}{$\Delta T_{\mathrm{s}}\left[{ }^{\circ} \mathrm{C}\right]$} \\
\cline { 2 - 13 } & 0 & 2 & 4 & 6 & 8 & 10 & 12 & 14 & 16 & 18 & 20 & 30 \\
\hline 0 & - & $\bullet$ & $\bullet$ & $\bullet$ & $\bullet$ & $\bullet$ & $\bullet$ & $\bullet$ & $\bullet$ & $\bullet$ & $\bullet$ & $\bullet$ \\
\hline 28 & $\bullet$ & - & - & - & - & - & - & - & - & - & $\bullet$ & $\bullet$ \\
\hline 50 & $\bullet$ & - & - & - & - & - & - & - & - & - & $\bullet$ & $\bullet$ \\
\hline
\end{tabular}

ferent bridge free expansion lengths, see Figures 14 and 15. The results show that the admissible stress was not exceeded for all studied lengths and temperatures neither in tension ( $92 \mathrm{MPa}$ for both tracks) nor in compression (72 MPa for ballasted track and $92 \mathrm{MPa}$ for non-ballasted track).

The non-linear numerical analyses allow the following fundamental insights:

- All non-linear analyses show good agreement with the monitored longitudinal forces in the rails;

- The stress thresholds caused by the structural movement due to temperature effects stated in the UIC rail specification allow a free expansion length for bridges of around $150 \mathrm{~m}$ for an unloaded situation.

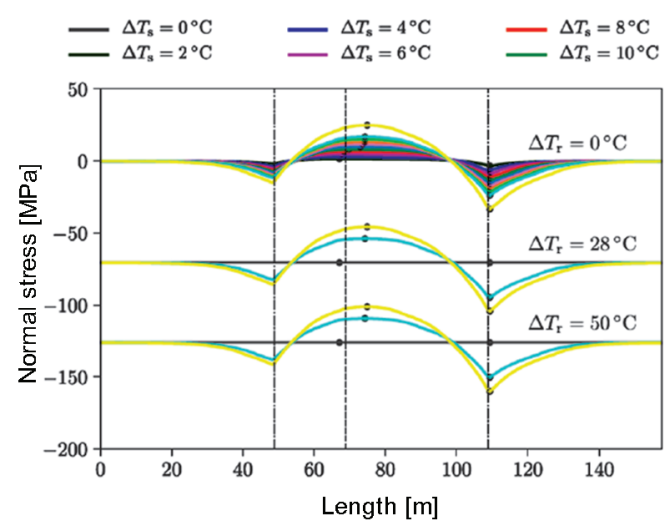

a)

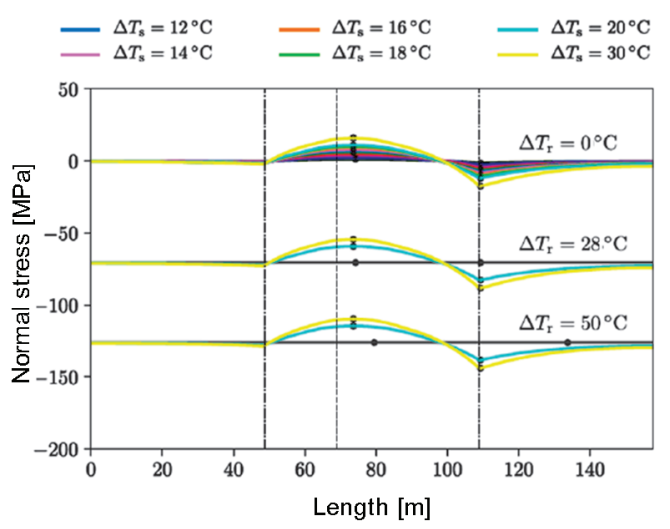

b)

Figure 13. Stress in the upper part of the rail - bridge free expansion length $L=40 \mathrm{~m}$ : a) non-ballasted track; b) ballasted track 


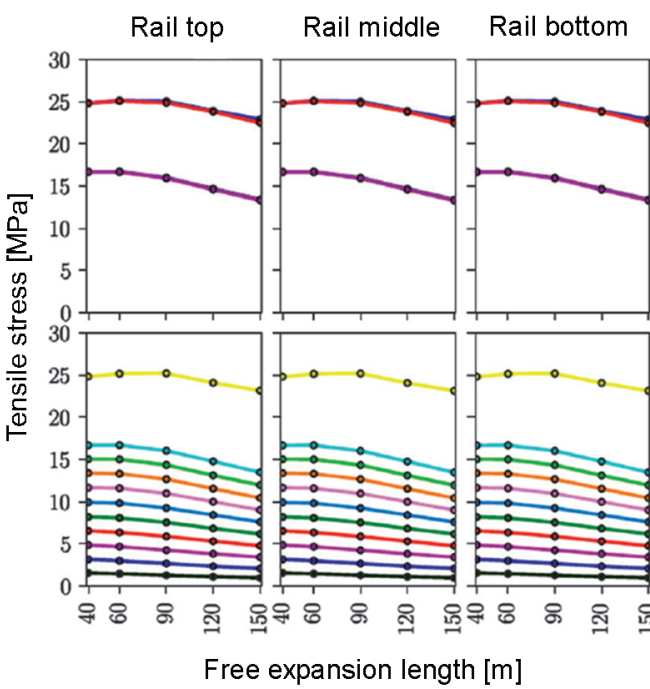

a)

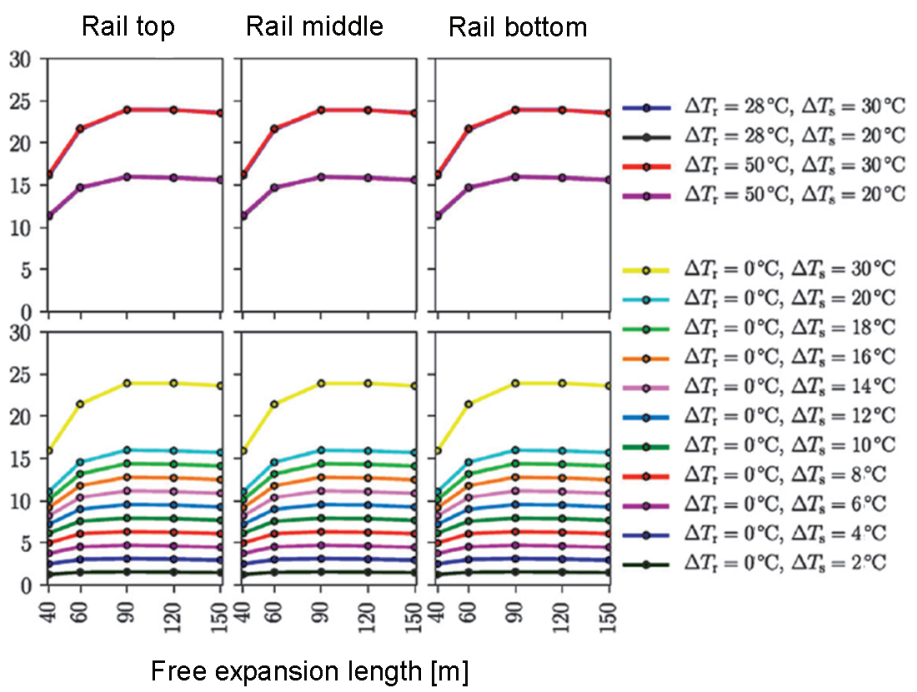

b)

Figure 14. Maximum tensile stress (admissible stress $\sigma_{\text {tension }}=92 \mathrm{~N} / \mathrm{mm}^{2}$ if bending is neglected) in individual parts of the rail for different values of free expansion length $L$ (see the bullets in the field in Figure 13):

a) non-ballasted track; b) ballasted track

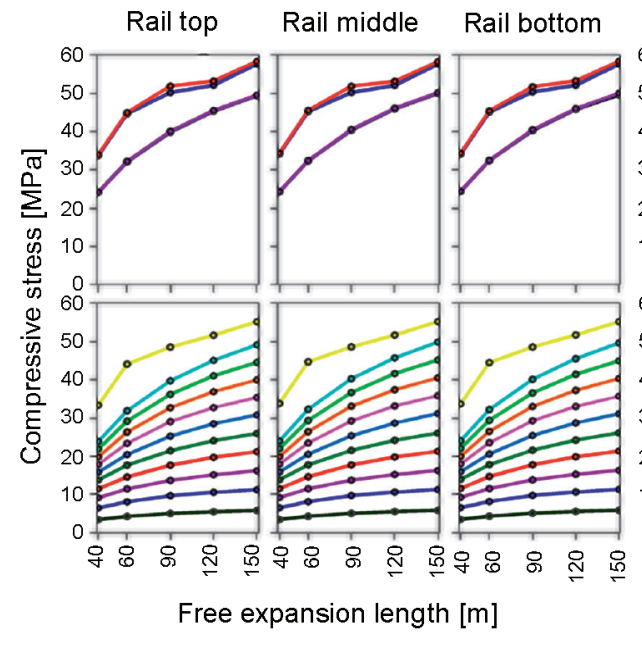

a)

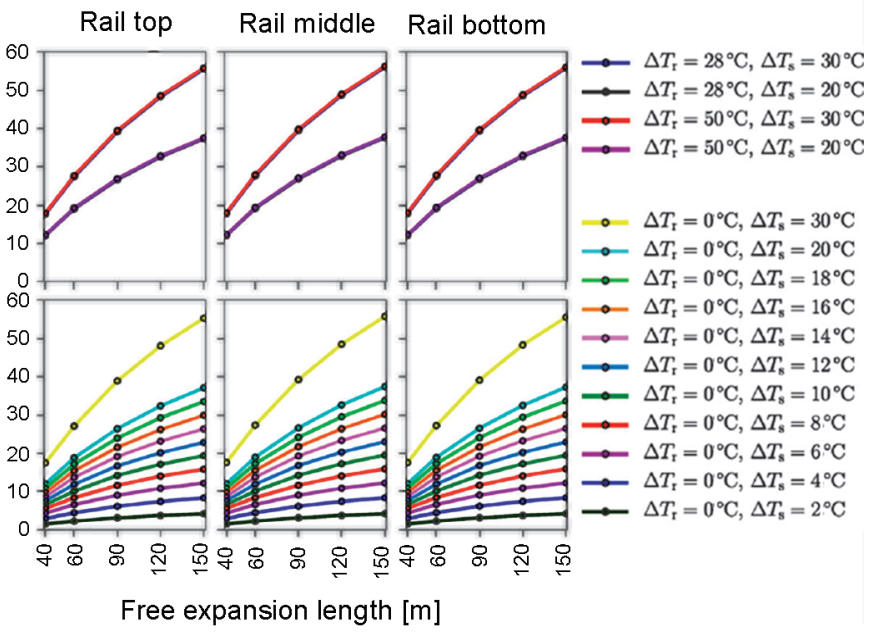

b)

Figure 15. Maximum compressive stress (admissible stress $\sigma_{\text {compression }}=92 \mathrm{~N} / \mathrm{mm}^{2}$ for non-ballasted track and $\sigma_{\text {compression }}=72 \mathrm{~N} / \mathrm{mm}^{2}$ for ballasted track) in individual parts of the rail for different values of free expansion length $L$ (see the bullets above the abutment in Figure 13): a) non-ballasted track; b) ballasted track

\section{Conclusions}

Complex nonlinear modelling of rail-bridge interaction provides an effective tool for the analysis and prediction of longitudinal stress in rail caused by the movement of the supporting structure. Since the properties of the rail clamp are different in the horizontal and vertical direction, an orthotropic material model was employed to transfer both horizontal and vertical forces corresponding to those obtained from experimental measurements and given in code specifications. Modelling included the calibration of rail boundary conditions with respect to seasonal in-situ measurements. The findings are as follows:
- The alternative modelling of rail structure connectors/interaction with the aid of composite material models is a new and promising method for overcoming the disadvantages of spring models, which (for instance) do not allow the incorporation of system and stiffness changes due to traversing trains;

- The modelling of the entire bridge using composite material models also shows significantly smoothed rail stress distribution caused by the temperature loading of rails and structures;

- The structure of the model also shows that the stress gradients are mainly caused by the end of the bridge 
due to the deformations of the structure. The temperature stresses in the rails have little effect on the stress gradients;

- With the calibrated nonlinear model, a numerical study was carried out in order to determine the effect of selected bridge free expansion lengths and temperature loads on the stress induced in a rail, which should not exceed the admissible stress capacity. In the case of tensile stress obtained in the field, the increase in structural temperature yields to an increase in stress. On the other hand, there is no increase in tensile stress due to the increase in the free expansion length of the bridge. This is probably due to the distribution of stress along the longer bridge length between supports;

- In the case of the compressive stress obtained above the abutments, the results are as expected, i.e. the compressive stress increases in response to both an increase in structural temperature and an increase in the bridge free expansion length;

- The results for non-ballasted as well as ballasted track confirmed that for all studied cases, i.e. for different temperatures and bridge free expansion lengths, the thresholds of admissible stress given in the codes for unloaded track were not exceeded even for a free expansion length of $150 \mathrm{~m}$, thus no expansion devices would be needed;

- Let us mention that similar studies performed for the same bridge but for loaded track resulted in a bridge free expansion length of up to $80 \mathrm{~m}$ without any need for expansion devices if the structural temperature reached $30{ }^{\circ} \mathrm{C}$ (not presented in this paper, for details see Strauss et al. 2018). Nevertheless, the probability of the simultaneous occurrence of loaded track (a stationary train) and such a high increase in structural temperature is very low.

\section{Acknowledgements}

This paper was produced under project No. 840500 "MAGIT - Monitoringbasierte Analyse der Gleis - Tragwerk Interaktion", supported by the Austrian Research Promotion Agency (FFG), and project No. LO1408 "AdMaS UP - Advanced Materials, Structures and Technologies", supported by the Ministry of Education, Youth and Sports of the Czech Republic under "National Sustainability Programme I". In this undertaking, theoretical results gained via project No. 17-02862S "PROMOSS" supported by the Czech Science Foundation were partially exploited.

\section{Disclosure statement}

The authors declare that they have no competing financial, professional, or personal interests in connection with other parties.

\section{References}

Cazzani, A.; Wagner, N.; Ruge, P.; Stochino, F. 2016. Continuous transition between traveling mass and traveling oscillator using mixed variables, International Journal of Non-Linear Mechanics 80: 82-95.

https://doi.org/10.1016/j.ijnonlinmec.2015.06.017

Červenka, V.; Jendele, L.; Červenka, J. 2012. ATENA program documentation - Part 1: theory. Prague: Cervenka Consulting Ltd.

Chaudhary, K. R.; Sinha, A. N. (n.d.). A study of various methods adopted by world railways to continue LWR over bridges. Course No. 623 Sr Professional Course (P WAY), S.R. Global University, India.

Chen, W. F.; Saleeb, A. F. 1982. Constitutive equations for engineering materials. John Wiley \& Sons.

Colnat, V.; Brems, W. 1983. Anfahrkräfte auf Brücken und Wechselwirkungen zwischen Gleisen und Brücken. Berechnung des Temperatureinflusses auf Brücken mit durchgehend geschweisstem Gleis (Theoritische Studien und Anwendungen). Utrecht: ORE.

DIN-Fb 101:2003. Einwirkungen auf Brücken [Actions on bridges]. Deutsches Institut für Normung, 2003 (in German).

EN 1991-2:2003 Eurocode 1: Actions on structures - Part 2. Traffic loads on bridges. European Committee for Standardization, 2003.

Esveld, C. 2001. Modern railway track. MRT-Production.

Frýba, L. 1996. Dynamics of railway bridges. Thomas Telford Ltd. https://doi.org/10.1680/dorb.34716

Gerlich, K.; Pahnke, U. 1981. Wechselwirkung Brücke-Gleis bei Abtragung von Längskräften, Eisenbahntechnische Rundschau 30(3): 225-229.

Gerlich, K.; Pahnke, U. 1982. Abtragung der Längskräfte im eisenbahnbrückenbau, Archiv Für Eisenbahntechnik 37: 19-30.

Karimi, S. 2017. Monitoring basierte Analyse der Gleis Tragwerke Interaktion, MAGIT: Dissertation. Institut für Konstruktiver Ingenieurbau, Universität für Bodenkultur Wien. In progress.

Kerr, A. D. 1978. Analysis of thermal track buckling in the lateral plane, Acta Mechanica 30: 17-50. https://doi.org/10.1007/BF01177436

Kerr, A. D. 1980. An improved analysis for thermal track buckling, International Journal of Non-Linear Mechanics 15(2): 99-114. https://doi.org/10.1016/0020-7462(80)90004-9

Klaaßen, K.; Schmälzlin, G. 1980. Berechnung der Längskräfte in hohen Eisenbahnbrücken bei nichtlinearem Materialgesetz des Schotters, Bautechnik 57(8): 279-280.

Kupfer, R. 2002. Untersuchung der während einer Zuguberfahrt im Gleis auftretenden Längsbewegungen, in Schriftenreihe Prüfamtes für Bau von Landverkehrswegen der TU München, München, 37-46.

Lim, N.-H.; Park, N.-H.; Kang, Y.-J. 2003. Stability of continuous welded rail track, Computers \& Structures 81(22-23): 2219-2236. https://doi.org/10.1016/S0045-7949(03)00287-6

Monnickendam, A. 2006. Track/bridge interaction and direct track fixing, in The $3^{\text {rd }}$ Network Rail Sponsored Supplier Conference on the Maintenance and Renewal of Bridges, Bristol, 61-64.

Pahnke, U. 1998. Einfluß der Biegung einer Eisenbahnbrücke auf die Schiene in Längsrichtung, Stahlbau 67(8): 634-641. https://doi.org/10.1002/stab.199802180 
PORR AG. 2016. Slab track Austria - System ÖBB-PORR elastically supported slab [online], [cited 5 July 2017]. Available from Internet: http://www.slabtrackaustria.com/fileadmin/ content/39_SlabTrackAustria/04_Download/slab_track_austria_brochure_feste_fahrbahn_160826_e.pdf

Prommersberger, G.; Rojek, R. 1981. Grundsatzuntersuchung zur Abtragung der Längkräfte auf Talbrücken, Eisenbahningenieur 32: 383-395.

Prommersberger, G.; Rojek, R. 1985. Tragsysteme zur Abtragung von Längskräften auf Eisenbahnbrücken, Eisenbahningenieur 36: 344-350.

Ruge, P.; Birk, C.; Muncke, M.; Schmälzlin, G. 2005a. Schienenlängskräfte auf Brücken bei nichtlinearer überlagerung der Lastfälle Temperatur, Tragwerksbiegung, Bremsen, Bautechnik 82(11): 818-825. https://doi.org/10.1002/bate.200590234

Ruge, P.; Schmälzlin, G.; Trinks, C. 2005b. Schienenlängskräfte auf Brücken infolge Biegung, Bautechnik 82(2): 69-80. https://doi.org/10.1002/bate.200590048

Ruge, P.; Trinks, C.; Muncke, M.; Schmälzlin, G. 2004. Längskraftbeanspruchung von durchgehend geschweißten Schienen auf Brücken für Lastkombinationen, Bautechnik 81(7): 537548. https://doi.org/10.1002/bate.200490125

Ruge, P.; Widarda, D. R.; Birk, C., 2009a. Longitudinal rail forces on railway bridges during passing of trains, Bautechnik 86(11): 677-694. https://doi.org/10.1002/bate.200910067

Ruge, P.; Widarda, D. R.; Schmälzlin, G.; Bagayoko, L. 2009b. Longitudinal track-bridge interaction due to sudden change of coupling interface, Computers \& Structures 87(1-2): 4758. https://doi.org/10.1016/j.compstruc.2008.08.012

Ruge, P.; Widarda, D.; Birk, C. 2007. Longitudinal track-bridge interaction for load-sequences, in R. Calçada et al. (Eds.). Track-bridge interaction on high-speed railways: Selected and revised papers from the workshop on "Track-bridge interaction on high-speed railways”, 15-16 October 2007, Porto, Portugal, 93-116.

Simões, R.; Calçada, R.; Delgado, R. 2007. Track-bridge interaction in railway lines: numerical modelling and application, in R. Calçada et al. (Eds.). Track-bridge interaction on highspeed railways: Selected and revised papers from the workshop on "Track-bridge interaction on high-speed railways", 15-16 October 2007, Porto, Portugal, 205-216.

Strauss, A.; Karimi, S.; Šomodíková, M.; Lehký, D.; Novák, D.; Frangopol, D. M.; Bergmeister, K. 2018. Monitoring-based nonlinear system modeling of bridge-continuous welded rail interaction, Engineering Structures 155: 25-35.

https://doi.org/10.1016/j.engstruct.2017.10.053

UIC Code 774-3R:2001 Track/bridge interaction - Recommendations for calculations. Union Internationale des Chemins de fer, 2001.

Wenner, M.; Lippert, P.; Plica, S.; Marx, S. 2016a. Track-bridge interaction. Part 1: Historical development and model, Bautechnik 93(2): 59-67. https://doi.org/10.1002/bate.201500107

Wenner, M.; Lippert, P.; Plica, S.; Marx, S. 2016b. Track-bridge interaction. Part 2: Background to the verification method, Bautechnik 93(7): 470-481.

https://doi.org/10.1002/bate.201600034 